\title{
Impact damage reduction by structured surface geometry
}

Kusano, Yukihiro; Fedorov, Vladimir; McGugan, Malcolm; Andersen, Tom L.; Johansen, Nicolai FrostJensen

Published in:

Materials Letters

Link to article, DOI:

10.1016/j.matlet.2018.03.146

Publication date:

2018

Document Version

Peer reviewed version

Link back to DTU Orbit

Citation (APA):

Kusano, Y., Fedorov, V., McGugan, M., Andersen, T. L., \& Johansen, N. F-J. (2018). Impact damage reduction by structured surface geometry. Materials Letters, 221, 296-300. https://doi.org/10.1016/j.matlet.2018.03.146

\section{General rights}

Copyright and moral rights for the publications made accessible in the public portal are retained by the authors and/or other copyright owners and it is a condition of accessing publications that users recognise and abide by the legal requirements associated with these rights.

- Users may download and print one copy of any publication from the public portal for the purpose of private study or research.

- You may not further distribute the material or use it for any profit-making activity or commercial gain

- You may freely distribute the URL identifying the publication in the public portal

If you believe that this document breaches copyright please contact us providing details, and we will remove access to the work immediately and investigate your claim 


\title{
Impact damage reduction by structured surface geometry
}

\author{
Yukihiro Kusano ${ }^{1}$, Vladimir Fedorov ${ }^{1}$, Malcolm McGugan ${ }^{1}$, Tom L. Andersen ${ }^{1}$, Nicolai Frost-Jensen \\ Johansen $^{2}$ \\ ${ }^{1}$ Department of Wind Energy, Technical University of Denmark, Ris $\varnothing$ Campus, 4000 Roskilde, Denmark \\ 2 Department of Mechanical Engineering, Technical University of Denmark, Lyngby Campus, 2800 \\ Lyngby, Denmark \\ *Correspondence: e-mail yuki@dtu.dk
}

\begin{abstract}
Repeated impacts can cause damage to not only a surface but also inside the material. Mechanisms include stress-wave propagation into the material, reflection of the waves at the back surface, and subsequent repeated reflections in the vicinity of the impact and the back surface. Impact damage performance was observed for polyurethane-coated fibre composites with structured geometries at the back surfaces. Repeated impacts by rubber balls on the coated side caused damage and delamination of the coating. The laminates with structured back surfaces showed longer durability than those with a flat back surface. The in-situ acoustic measurement indicates that the acoustic power within the pulse duration was $25-40 \%$ lower using the structured back surfaces. The observed effect can be attributed to scattered reflection at the back surface to reduce the high intensity duration of the acoustic waves.
\end{abstract}

Keywords: Impact damage; acoustic wave; reflection; fibre reinforced polymer; coating

\section{Introduction}

Composite materials are used in many engineering and structural applications [1], including automobiles, aircrafts, ballistic applications, and wind turbine blades [2]. They are often severely exposed to repeated impact loadings, affecting life of the structural materials. An example is the leading edge of a wind 
turbine blade exposed to raindrops, hailstones, particles, and wild life [3]. The impact load thereof may be high especially near the tip of large wind turbine blades rotating at speeds approaching to $100 \mathrm{~m} / \mathrm{s}$ [3]. Therefore, even impacts of small substances can result in serious damage. It is believed that these loadings give rise to erosive damage to the wind turbine blades. Significant efforts have been made to study the rain erosion phenomena [4-6], develop damage protective coatings and assess the lives of the leading edges $[3,7,8]$. It is reported that polyurethane based coatings show good erosion resistant properties [8]. However, due to the future demands for still larger blades at higher tip speeds, the performances of the existing damage protection techniques will be unsatisfactory, and further efforts have to be made.

Although impact stress waves propagating through the protective coating are presented [3-7], structural design assessment to reduce leading edge erosion is not considered. Wind turbine blades are typically constituted of fibre reinforced polymer composites, called laminates. A study of repeated impacts to laminates has shown that the fracture starts inside the laminate [9], suggesting that tensile stress waves reflected at the back surface opposing the impact surface play an important role in the early internal damage. Such internal damage is difficult to detect on a component in use, and a resulting sudden failure can be serious. Hence, an improved design of structural components with high impact resistance would be advantageous.

Damping of impact stress waves can reduce the damage [10,11]. However, adding damping properties to the laminate may restrict the choice of optimal material as a structural component.

The direction of acoustic wave propagation can be controlled by carefully defining the geometry of a material surface or interface at which the acoustic wave can reflect. It is reported that traffic noises can be reduced by re-orienting the direction of the acoustic waves in air using reflection panels [12]. However, similar attempts for dissipating acoustic waves in solid materials are significantly limiting. Only one publication relevant to this issue is related to a plural layer composite armor system, in which ceramic elements with textured back surface are embedded [13]. A projectile striking at the composite armor system can penetrate into the composite and is blocked by the embedded ceramic, generating shock waves. It is indicated that in the prior art without the textured back surface of the ceramics, the complex interaction of the incident shock waves and the reflected shock waves can result in internal failure of the ceramic element [13]. It is argued that the proposed textured ceramics enables reflected shock waves at 
the backside of the ceramics to temporally and spatially diverge so that the interaction between the incident and reflective shock waves can be significantly reduced [13]. However, the technique cannot be readily applied to the structural design of the wind turbine blades. First, impact particles (rain drops) typically do not penetrate into the wind turbine blades. Second, difference in acoustic impedances between the embedded ceramic and surrounding material is low, and subsequently, acoustic reflection at the interface between the ceramic and the surrounding material is insignificant. Furthermore, there is a risk that introducing such a ceramic may induce inferior mechanical properties.

In the present work, polyurethane coated glass fibre reinforced polymer (GFRP) laminates were manufactured with special geometries of the back surfaces so as to change the stress wave reflections thereof, aiming at reducing impact damage. Repeated impacts were applied on the coated side of the laminate. Video monitoring and acoustic measurement around the impact location on the coated surface were carried out in-situ.

\section{Experimental methods}

A flat GFRP laminate was manufactured by vacuum infusion of a symmetric glass fibre layup (Biax/4xUD/Biax/4xUD/Biax/Biax/4xUD/Biax/4xUD/Biax) using Ahlstrom UD1150+Biax100 and Biax600 glass fibre fabric combined with a Huntsmann epoxy resin Araldite ${ }^{\circledR}$ LY1564/Aradur ${ }^{\circledR} 3487$. The laminate was cured at $40^{\circ} \mathrm{C}$ for $19 \mathrm{~h}$ and post-cured at $80{ }^{\circ} \mathrm{C}$ for $5 \mathrm{~h}$, and cut into $15 \mathrm{~mm}$ thick laminates with a shape of $150 \mathrm{~mm} \times 150 \mathrm{~mm}$. Three different designs of the back surfaces were employed. The first laminate, referred to as a flat laminate, has a flat back surface and the thickness was reduced to approximately $13 \mathrm{~mm}$ so that the mass of the laminate would be close to those of two other structured laminates. The second laminate, referred to as a striped laminate, has a linearly striped pattern. The cross-section perpendicular to the linear stripe shows a regular zigzag structure with approximately $45^{\circ}$ slopes relative to the back surface. The adjacent peaks and the adjacent valleys have a pitch of approximately $1.0 \mathrm{~cm}$. The pattern was milled from the original $15 \mathrm{~mm}$ thick laminate. The third laminate, referred to as a pyramidal laminate, was a further modification of the second laminate by rotating it by $90^{\circ}$ and performing the same milling for manufacturing the second laminate. As a result, each convex has a pyramidal shape. The images of these laminates are shown in Figure 1. The measured 
mass of the flat, striped and pyramidal laminates, are $556.3 \mathrm{~g}, 566.9 \mathrm{~g}$, and $527.9 \mathrm{~g}$, respectively. Each of the laminates was further cut into 9 pieces, sized $47 \mathrm{~mm} \times 47 \mathrm{~mm}$ to fit the device for impact testing. Side photographic views of the cut laminates are added as insets.
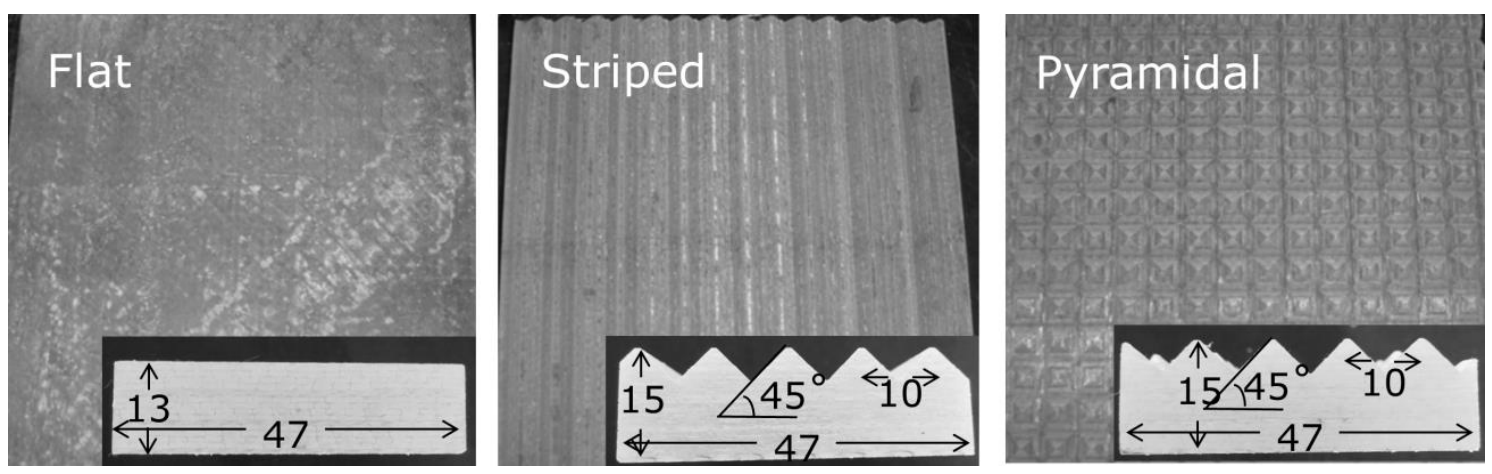

Figure 1. Images of the back surfaces of the flat, striped and pyramidal laminates $(150 \mathrm{~mm} \times 150 \mathrm{~mm})$. Side views of the cut specimens as insets (unit of length in $\mathrm{mm}$ ).

The foreside of each laminate opposite to the back surface was cleaned with acetone and ethanol. Transparent polyurethane coating was applied by spraying (Polyurethane KLAR LAK, plasti-kote). The thickness and hardness of the dried and cured coating were estimated to be approximately $1 \mu \mathrm{m}$ and at least $0.2 \mathrm{GPa}$, respectively. A home-made impact tester was used to apply repeated impacts on the coating side of the laminates.

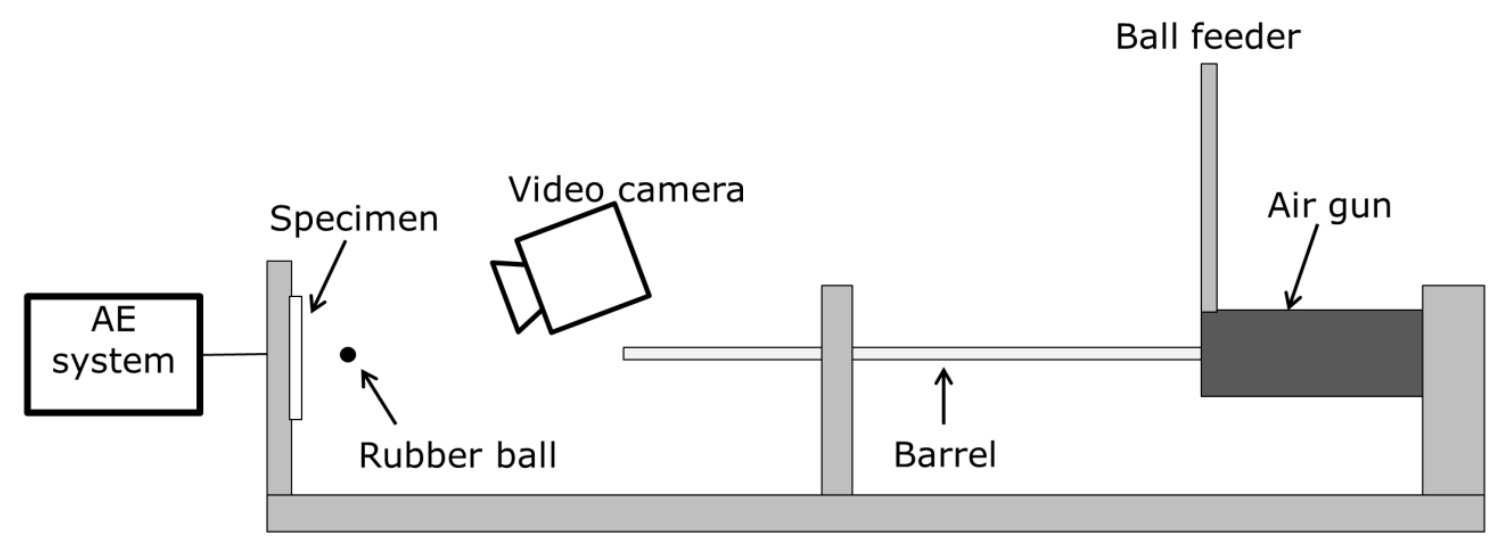

Figure 2. A schematic diagram of the impact tester. 
Figure 2 shows a schematic diagram of the setup. A 6-mm diameter rubber ball was fed to an end of a barrel one by one by a ball feeder. Compressed air was released with a predetermined interval to accelerate the ball through the barrel. The ball hit substantially at a same location on the coating at a speed of $165 \mathrm{~m} / \mathrm{s}$ with a frequency of $1 \mathrm{~Hz}$. During testing the impact area and its vicinity were monitored using a digital microscope camera. More detailed description can be found in [14].

An acoustic emission (AE) sensor (miniature Nano30 sensor, Mistras Group inc.) was mounted within 20 $\mathrm{mm}$ from the impact location on the coated surface to detect elastic stress waves caused by the impacts. The detected signals were amplified and the resulting waveform was delivered to the AE system which processes the information. An amplitude, an average frequency of the reflected signal, a duration and a relative energy [15] of the AE signal were measured. Furthermore, the relative energy per the duration corresponding to the acoustic power within a pulse duration was calculated, indicating the average power of the AE signal over the pulse duration.

\section{Results and discussion}
$0 \mathrm{~s}$
$15 \mathrm{~s}$
$30 \mathrm{~s}$
$60 \mathrm{~s}$
$90 \mathrm{~s}$
$120 \mathrm{~s}$

(a) Flat
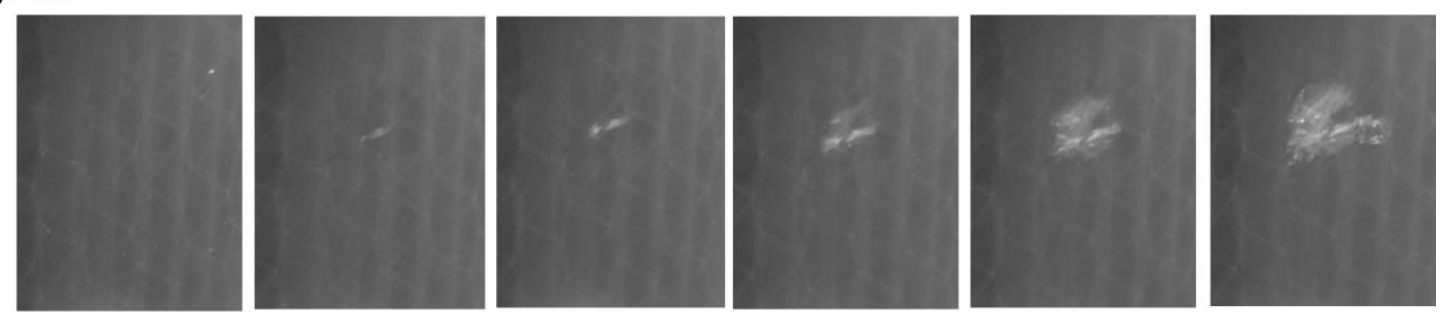

(b) Striped
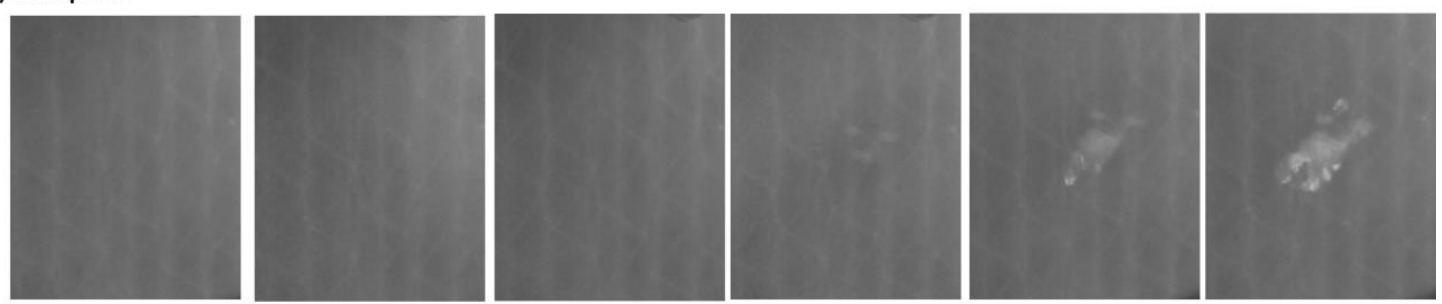

(c) Pyramidal
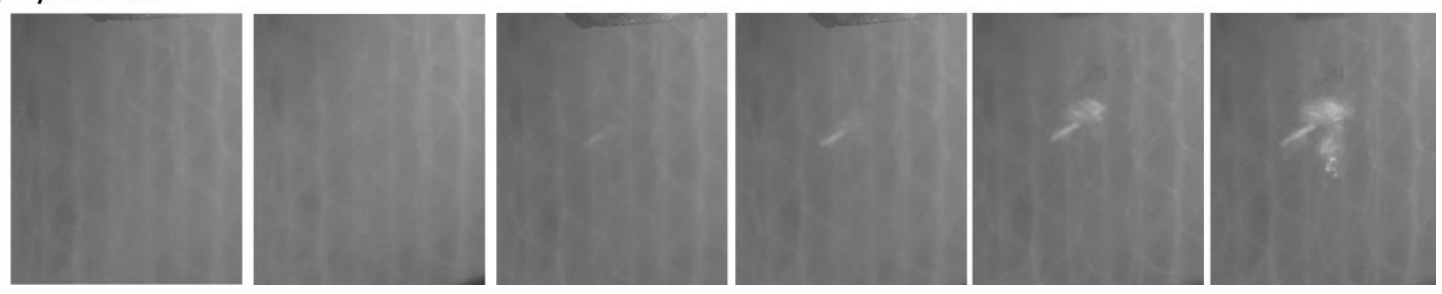

Figure 3. Images the coated surfaces after different impact durations (approximately $20 \mathrm{~mm} \times 25 \mathrm{~mm}$ ). 
Photo images of the coated surfaces were taken in-situ during the impact test. The coating of the flat laminate was damaged at $9 \mathrm{~s}$, characterized by coating delamination, and thereafter, the delamination spread steadily (Figure 3 (a)). On the other hand, the damage of the coatings of the striped and pyramidal laminates started at 48 and 30s, respectively. The result indicates that the structured back can delay the impact damage significantly (Figure $3(b, c)$ ).

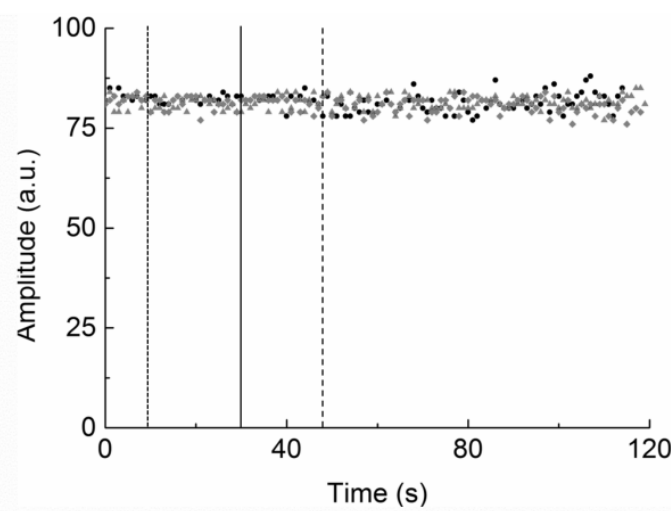

(a) Amplitude.

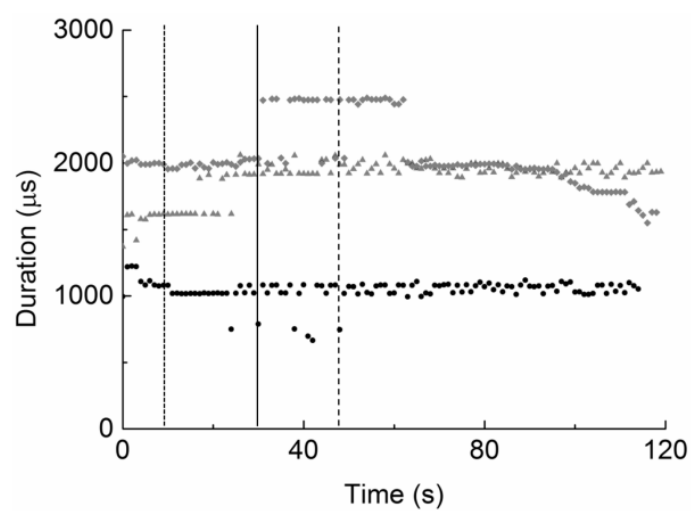

(c) Duration.

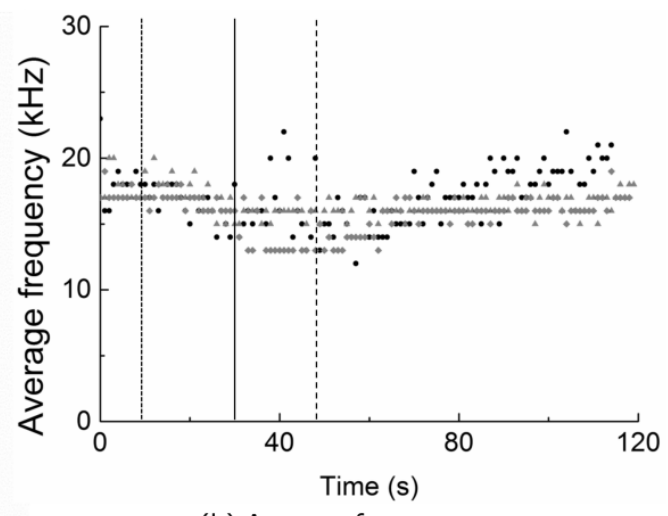

(b) Average frequency.

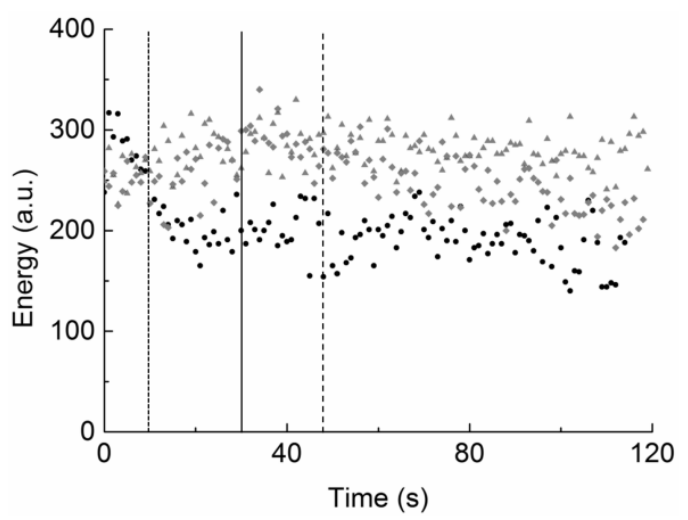

(d) Energy.

Figure 4. AE measurements during the repeated impacts. Circle: flat, triangle: striped, and diamond: pyramidal. Visual damage initiation is indicated by dashed (flat), dotted (striped) and solid (pyramidal) lines.

The stress waves are reflected when they meet a boundary between two materials having significantly different acoustic impedances. This can happen at an interface or interphase between two different materials, or at the back surface. A typical diameter of the glass fibres in the laminate is in the order of $10^{-}$ 
${ }^{5} \mathrm{~m}$, while the representative wavelength of the stress wave simulated is in the order of $10^{-2}-10^{-3} \mathrm{~m}$. Therefore, the dimension of a fibre is significantly smaller than the wavelength of the stress wave, and the stress wave will not distinguish the change in acoustic impedance at the fibre-matrix interface. As a result, there will not be any scattering or reflection at the fibre-matrix interface. On the other hand, a ratio of the acoustic impedances between a solid and atmospheric air is typically in the range of $10^{4}-10^{5}$ and the most of the stress wave propagating from the impact point through the coating and the laminate will reflect at the back surface. The reflected wave propagates back through the laminate and the coating, and reflects at the front surface. If the front and back surfaces are substantially parallel and flat, and incident impact is substantially perpendicular to the front surface, it is likely that stress waves reflected at the front and back surfaces may interact significantly. Ref. [9] argues that this may be the cause of the observed initial damage in the laminate. It is expected that the structured back surfaces in the present work can efficiently reorient the reflected waves at the back surface so that this effect can be reduced. The overall amplitudes of the AE signals among the three specimens do not differ (Figure 4 (a)). The amplitude may be mainly associated with the surface waves as a direct result of the impact, and thus influence of the back surface design might be insignificant. The measured average frequencies are also similar as shown in Figure 4 (b). The frequency is generally associated with a characteristic length, that is, thickness of the laminates. Since the average thickness of the laminates is similar, the measured results are thought to be reasonable. Assuming that the acoustic wave velocity in the laminate is in the order of $10^{3} \mathrm{~m} / \mathrm{s}$, the wavelength of the acoustic wave is in the order of $10^{0}-10^{1} \mathrm{~cm}$, which is not far from the thickness of the laminates.

On the other hand, the duration and energy of the flat laminate are significantly lower than those of the striped and pyramidal laminates (Figure $4(\mathrm{c}, \mathrm{d})$ ). It is probably due to the effective re-orientation of the reflection waves at the structured back surfaces, diluting the intensity of the impact waves at the impact location. Here, the AE measurement was made not at the impact location but its vicinity, rather measuring the re-oriented reflection waves as well as the surface waves. In other words, the higher AE energy may indicate pronounced re-orientation of the reflection at the back surface. The in-situ AE measurement indicates that duration of measured acoustic waves per impact for the laminates with structured back surfaces is $30-80 \%$ longer than that for the laminates with flat surfaces, and that the measured acoustic power within the pulse duration of the laminates with structured back surfaces is $25-40 \%$ lower than that 
of the laminate with flat back surfaces as summarised in Table 1. It is suggested that the reduced acoustic power within the pulse duration can reduce damage in the material, thereby prolonging the life of the laminate.

Table 1. AE measurement results for flat, striped and pyramidal laminates.

\begin{tabular}{|c|c|c|c|c|c|}
\hline & $\begin{array}{c}\text { Amplitude } \\
(\mathrm{dB})\end{array}$ & $\begin{array}{c}\text { Duration } \\
(\mu \mathrm{s})\end{array}$ & $\begin{array}{c}\text { Average } \\
\text { frequency }(\mathrm{kHz})\end{array}$ & $\begin{array}{c}\text { Energy } \\
(\text { a.u. })\end{array}$ & $\begin{array}{c}\text { Power within pulse } \\
\text { duration (Enery/ms) }\end{array}$ \\
\hline Flat & 82 & 1042 & 17 & 202 & 194 \\
\hline Striped & 81 & 1889 & 17 & 280 & 123 \\
\hline Pyramidal & 81 & 2048 & 16 & 253 & \\
\hline
\end{tabular}

There is an additional prospective advantage in structured back surfaces for impact damage reduction, in particular for an anisotropic material such as fibre reinforced composites. Along the direction of fibre orientation(s), the composite is stiffer. On the other hand, the composite is weaker in a direction perpendicular to the fibre orientation. In many cases, the directions of the impact by e.g. rain and the reflected waves are approximately perpendicular to the fibre orientation. This is the direction of lowest strength and the impact failure is likely to occur. The direction of the impact cannot be changed. However, the result of the present work suggests that the reflection wave can be re-oriented to become closer to the stiffer direction of the composite. Such effects can be expected with a variety of designs with regular or irregular patterns so that the risk of impact damage is decreased.

For more reliable experimental results of such an impact fatigue test, performing multiple experiments is desirable to avoid statistic errors, which will be carried out in the future work. However, a separate AE measurement of another flat specimen shows high reproducibility, supporting the concept of the effect of the structured back surfaces in the present work.

\section{Conclusion}


Polyurethane coated laminates with the flat, striped and pyramidal structured back surfaces were subjected to repeated impact test. The striped and pyramidal laminates showed longer durability of the coatings than the flat laminate, linked to the acoustic power within the pulse duration. There is potentially an additional advantage in employing the structured back surface to the anisotropic materials.

\section{Acknowledgement}

The authors are grateful to Christian H. Madsen for designing and manufacturing structured specimens. This research did not receive any specific grant from funding agencies in the public, commercial, or notfor-profit sectors.

\section{References}

[1]. M.A. Meyers, K.K. Chawla, Mechanical Behavior of Materials, Cambridge University Press. 2009.

[2]. P. Brøndsted, H. Lilholt, A. Lystrup, Composite materials for wind power blades, Annu. Rev. Mater. Res. 35 (2005) 505-538.

[3]. M.H. Keegan, D.H. Nash, M.M. Stack, On erosion issues associated with the leading edge of wind turbine blades, J. Phys. D Appl. Phys. 46 (2013) 383001.

[4]. A. Castorrini, A, Corsini, F. Rispoli, P. Venturini, K. Takizawa, T.E. Tezduyar, Computational analysis of wind-turbine blade rain erosion, Computers and Fliuds 141 (2016) 175-183.

[5]. B. Amirzadeh, A. Louhghalam, M. Raessi, M. Tootkaboni, A computational framework for the analysis of rain-induced erosion in wind turbine blades, part I: Stochastic rain texture model and drop impact simulations, J. Wind Eng. Industrial Aerodynamics, 163 (2017) 33-43.

[6]. B. Amirzadeh, A. Louhghalam, M. Raessi, M. Tootkaboni, A computational framework for the analysis of rain-induced erosion in wind turbine blades, part II: Drop impact-induced stresses and blade coating fatigue life, J. Wind Eng. Industrial Aerodynamics, 163 (2017) 44-54.

[7]. E.A. Valaker, S. Armada, S. Wilson, Droplet erosion protection coatings for offshore wind turbine blades, Energy Procedia 80 (2015) 263-275. 
[8]. H.M. Slot, E.R.M. Gelink, C. Rentrop, E. van der Heide, Leading edge erosion of coated wind turbine blades: Review of coating life models, Renewable Energy 80 (2015) 837-848.

[9]. G. Prayogo, H. Homma, T. P. Soemardi, A.S. Danardono, Impact fatigue damage of GFRP materials due to repeated raindrop collisions, Trans. Indian Inst. Met. 64 (2011) 501-506.

[10]. I.C. Finegan, R.F. Gibson, Recent research on enhancement of damping in polymer composites, 44 (1999) 89-98.

[11]. R.D. Friend, V.K. Kinra, Particle impact damping, J. sound and Vibration, 233(1) (2000) 93-118.

[12]. M. Murase, H. Kudo, K. Mizuno, Interference noise-control unit, EP 0742545 B1 (2002)

[13]. C.A. Martin, G.F. Lee, J.J. Fedderly, Composite armor including geometric elements for attenuating shock waves, US 8,096,224 B2 (2012).

[14]. A. Fraisse, J.I. Bech, K.K. Borum, V. Fedorov, N.F.-J. Johansen, M. McGugan, L. Mishnaevsky, Y. Kusano, Impact fatigue damage of coated glass fibre reinforced polymer laminate, Renewable Energy, submitted.

[15]. A. Barchan, The analysis of fatigue damage to glass-fiber reinforced composites, Mater. Sci. 37(6) (2001) 918-927. 